\title{
Hepatocellular Carcinoma in Benin City, Nigeria: A Twenty-Five (1987-2011) Year Retrospective Histopathological Study
}

\author{
I. G. Nnadi ${ }^{1}$ (), A. N. Olu-Eddo², D. E. Obaseki ${ }^{2}$ \\ ${ }^{1}$ Department of Pathology, FMC, Owerri, Imo State, Nigeria \\ ${ }^{2}$ University of Benin Teaching Hospital, Benin City, Edo State, Nigeria \\ Email: godheniknnd@yahoo.com
}

How to cite this paper: Nnadi, I.G., OluEddo, A.N. and Obaseki, D.E. (2019) Hepatocellular Carcinoma in Benin City, Nigeria: A Twenty-Five (1987-2011) Year Retrospective Histopathological Study. Health, 11, 1177-1185.

https://doi.org/10.4236/health.2019.119092

Received: April 15, 2019

Accepted: September 26, 2019

Published: September 29, 2019

Copyright $\odot 2019$ by author(s) and Scientific Research Publishing Inc. This work is licensed under the Creative Commons Attribution International License (CC BY 4.0).

http://creativecommons.org/licenses/by/4.0/

\begin{abstract}
Aim: To evaluate the demographic characteristics and histological variants of hepatocellular carcinoma (HCC) in Benin City. Methodology: The surgical daybooks of the Department of Anatomic Pathology, University of Benin Teaching Hospital were used for data collection. All the liver biopsies received in the period (1987-2011) under review diagnosed with HCC were analysed using SPSS version 16.0. Results: The male to female ratio was 2:1 and the peak age of incidence was in the 50 - 60 years age group. The mean ages were $44.24 \pm 18.52$ and $48.75 \pm 12.92$ and the age ranges were 1.5 to 82 years and 20 to 68 years for males and females respectively. The modal age was 60 years. Histological variants of hepatocellular carcinoma were the pseudoglandular/acinar pattern which accounted for 26 cases $(44.07 \%)$, followed by the trabeculae pattern 17 cases $(28.81 \%)$, the compact/solid variant 10 cases $(16.95 \%)$ and the fibrolamellar pattern which was 6 cases $(10.17 \%)$. Conclusion: Hepatocellular carcinoma has divergent demographic and histological characteristics which have clinical implications on the treatment outcomes; hence pathologists are encouraged to include the subtype in their reports for prognostication.
\end{abstract}

\section{Keywords}

Hepatocellular Carcinoma, Benin City, Nigeria

\section{Introduction}

Hepatocellular carcinoma (HCC) is the fourth leading cause of cancer death worldwide [1]. HCC has a wide variation in its incidence in different parts of the world, East Asia and Sub-Saharan Africa has the highest number of cases [2]. In 
South-East Asia and Sub-Saharan Africa, 10 - 30 new cases per 100,000 males were reported each year, whereas, in northern Europe, North America and Australia, the annual incidence rates of HCC were less than 3 cases per 100,000 males [3]. Several reports from different parts of Nigeria demonstrated that HCC is the second, third, fourth and ninth most frequent cancer in Lagos, Ilorin, Jos, and Sokoto, respectively [4] [5] [6] [7]. In Ghana, Wiredu et al. [8] reported that HCC is the third most frequent malignancy in the female after cancer of the uterine cervix and breast. The incidence of HCC in Eastern, Central, and Western Africa is 24.2, 14.4 and 13.5 per 100,000 males respectively [9]. However, lower incidence rates were reported in northern (4.9/100,000 males) and southern (6.2/100,000 males) Africa which have incidence rates similar to Europe [9]. The Middle East has lower incidence rates of HCC when compared to South East Asia and Africa, with variations among different countries [10]. Moreover, Murugavel et al. [11] reported very low incidences of $0.2 \%$ to $1.9 \%$ of HCC in India compared to China, Japan, and other Southeast Asian countries.

Hepatocellular carcinoma is a complex tumour with variable histomorphological appearance [12]. The World Health Organization (WHO) recognised histological variants are scirrhous HCC, fibrolamellar carcinoma, combined HCC-cholangiocarcinoma (HCC-CC), sarcomatoid HCC, undifferentiated carcinoma, and lymphoepithelioma-like HCC. Other subtypes including clear cell HCC, diffuse cirrhosis-like HCC, steatohepatitic HCC, transitional liver cell tumour, and College of American Pathologist (CAP) carcinoma are also recognised [13]. Several reports demonstrated that histomorphological variants of HCC are strong independent prognostic factors in the determination of treatment outcomes [14] [15] [16] [17]. For instance, reports indicate that clear cells, fibrolamellar and lymphoepithelioma-like variants have a better prognosis than the giant cell, combined cholangiohepatocellular and sarcomatoid variants and that the former group has better survival post-liver transplant [13] [14] [15] [18] [19]. Thus, some reports categorised these variants as low grade with favourable prognosis and high grade with worse outcomes respectively [13] [18]. Moreover, Jain et al. [20] reported that pedunculated and ablated HCC variants are also prognostically favourable. All these prognostic indices are products of the molecular biology of these tumours. For instance, Canderaro et al. [21] reported that every subtype of HCC has intrinsic molecular phenotype which is dependent on the different genetic mutations that underlay the individual histologic phenotype. These mutations and chromosome alterations are present in TERT promoter, CTNNB1, TP53, AXIN1, ARID1A, NFE2L2, ARID2 and RPS6KA3 to acquired influences from HBV [21]. Besides, Jain et al. [22] reported that steatohepatitic variant is frequently associated with metabolic risk factor, especially non-alcoholic fatty liver disease.

This is a study of the HCC diagnosed histologically in University of Benin Teaching hospital, Benin City South-south Nigeria with emphasis on the demographics and histological variants of the tumour. 


\section{Methodology}

This is a retrospective study. The period under review was 25 years (January 1 1987 to December 31 2011). The data were collected from surgical daybooks, glass slides, tissue blocks, histology request and report forms of the Department of Pathology, University of Benin Teaching Hospital Benin City, Edo State, Nigeria. The demographic parameters of the patients histologically diagnosed with HCC were obtained. The Haematoxylin and Eosin (H\&E) stained slides were reviewed and the histological variants of the hepatocellular carcinoma were recorded. In cases whose histology slides were damaged or missing, the formalin-fixed paraffin-embedded (FFPE) tissue blocks were selected and sectioned with a microtome. Fresh sections $(3-4 \mu)$ were processed on lysine coated glass slides, de-paraffinized with xylene, rehydrated in graded alcohol and stained with hematoxylin and eosin (H\&E). Those liver biopsies which did not meet the inclusion criteria were excluded from the study. The data were analysed with SPSS version 16.0

\section{Results}

A total of 235 liver biopsies were received in the Department of Histopathology, University of Benin Teaching Hospital, Benin City during the period under review. Fifty-nine (59) of these cases were diagnosed histologically with HCC.

Of the 59 confirmed cases of HCC, 39 cases $(66.10 \%)$ were male while 20 cases (33.90\%) were females giving a male to female ratio of 2:1. The age range for all the patients was 1.5 to 82 years with a peak incidence in the $51-60$ years age group which accounted for 13 cases (22.4\%). See Table 1 . The overall mean age was $48.16 \pm 16.55$ years. The modal age was 60 years. The age range for males and females were 1.5 to 82 years and 20 to 68 years, with a mean age of $44.24 \pm$ 18.52 and $48.75 \pm 12.92$ respectively.

The dominant histological variant of hepatocellular carcinoma was the pseudoglandular/acinar pattern which accounted for 26 cases (44.07\%), followed by

Table 1. The distribution of hepatocellular carcinoma for different age groups.

\begin{tabular}{cccc}
\hline S/n & Age & Freq. & $\%$ \\
\hline $\mathbf{1}$ & $1-10$ & 1 & 1.69 \\
2 & $11-20$ & 2 & 3.39 \\
$\mathbf{3}$ & $21-30$ & 5 & 8.47 \\
$\mathbf{4}$ & $31-40$ & 12 & 20.34 \\
$\mathbf{5}$ & $41-50$ & 12 & 20.34 \\
$\mathbf{6}$ & $51-60$ & 13 & 22.03 \\
$\mathbf{7}$ & $61-70$ & 10 & 16.95 \\
$\mathbf{8}$ & $71-80$ & 3 & 5.08 \\
$\mathbf{9}$ & $81-90$ & 1 & 1.69 \\
Total & & 59 & 100 \\
\hline
\end{tabular}


the trabecular pattern with 17 cases $(28.81 \%)$, the compact/solid variant with 10 cases $(16.95 \%)$ and the fibrolamellar pattern with 6 cases $(10.17 \%)$. These findings are depicted in Figure 1.

\section{Discussion}

HCC is 2 - 7 times more common in males than females worldwide [23] except in Iran where there is a slight female preponderance [10]. In our study, the male to female ratio was $2: 1$. The mean age was $44.24 \pm 18.52$ and $48.75 \pm 12.92$ with age range of 1.5 to 82 and 20 to 68 years for males and females respectively. The peak age of incidence was 51 - 60 years (22.03\%) followed by 31 - 40 and 41 - 50 age groups, which constituted $20.34 \%$ respectively. The gender ratio is relatively consistent with other reports from Enugu, Port Harcourt, Ile-Ife and Zimbabwe [24] [25] [26] [27]. However, the peak age of incidence in these reports are diverse, ranging from 20 - 39 in Enugu to 40 - 59 in Ile-Ife [24] [25] [26] [27]. In Kenya, Mutuma et al. [28] reported a male to female ratio of 5:2, mean age of 40 years and the peak age of incidence of 41 - 60 year age group. These reports demonstrated that HCC appears to be more prevalent between the ages of 30 and 70 years. In this study, $80 \%$ of all HCC occurred within this age range. In Pakistan, HCC is the second most prevalent liver disease and constituted $7.9 \%$ after viral hepatitis $(68.3 \%)$, with a male to female ratio of $1: 1$ and peak age of incidence of 31 - 50 years [28]. In our study, the youngest patient was aged 1.5 years compared to 14 and 17 years in Port Harcourt [23] and Zimbabwe [27] respectively. Leong and Schandy et al. [29] [30] reported that HCC may occur in children who were exposed to $\mathrm{HBV}$ infection early in life, children who have other risk factors like biliary atresia, inborn errors of metabolism (hereditary tyrosinemia, Wilson's diease, al-antitrypsin deficiency and glycogen storage disease), giant cell hepatitis of infancy and genetic alterations in cancer suppressor genes.

There are several histologic variants of hepatocellular carcinoma. These include the pseudoglandular, trabecular, scirrhous, clear cell, giant cell, sarcomatoid,

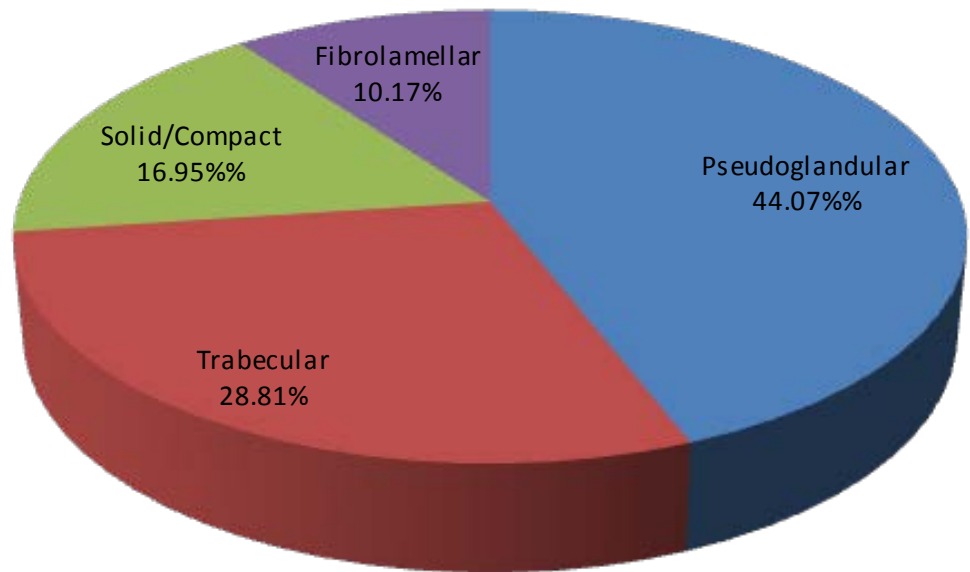

Figure 1. A pie chart showing the histological variants of hepatocellular carcinoma in Benin City. 
compact or solid type and fibrolamellar variants [2]. In this study, pseudoglandular pattern was observed in 24 cases (40.68\%), trabecular pattern in 17 cases (28.81\%), solid variants in 12 cases $(20.34 \%)$ and fibrolamellar pattern in 6 cases (10.16\%). In Port Harcourt, a city in the same geopolitical zone as Benin City, Seleye-fubara et al. [25] reported a different pattern. These histologic variants included trabecular/sinusoidal pattern 37 cases (49.3\%), pseudoglandular/acinar pattern 21 cases (28\%), compact/solid pattern 12 cases (16.09\%), clear cell type 3 cases (4.0\%) and fibrolamellar pattern 2 cases (2.7\%) [25]. In East Africa country of Kenya, Mutuma et al. [28] reported that the histological variants of HCC were compact/solid (48.8\%), trabecular (29.5\%), clear cell (10.3\%), scirrhous $(7.7 \%)$, giant cell (2.5\%) and pseudoglandular (1.2\%) types. These histological differences show that HCC can vary histologically even within the same geopolitical zone of a country or different regions of the same country or continent. In southern Thailand, Sooklim et al. [31] reported a marked reduction in the frequency of the pseudoglandular/acinar (5\%) and fibrolamellar (0.6\%) patterns. Moreover, Vhriterhire and Kashala et al. [32] [33] made similar observations in Jos, Nigeria, and Republic of Zaire respectively. However, $7.9 \%$ of hepatocellular carcinoma in Jos presented mixed histologic features of both trabecular and acinar patterns [32]. In all these reports, the fibrolamellar subtype maintained the least relative frequency, because it has no relationship with any predisposing factor [27]. Furthermore, Bello et al. [34] reported that the conventional histologic variant of hepatocellular carcinoma constituted more than $90 \%$ of all the tumor, followed by the clear cell variants. The sarcomatoid and the scirrhous variants had an equal frequency in their observations [34]. Besides, a very rare histologic variant is the inflammatory carcinoma of the liver called the lymphoepithelioma-like (LEL) variant. LEL may or may not be related to Epstein-Barr virus infection as other lymphoepithelial carcinomas [17]. These rare histologic subtypes of HCC have gross morphological and prognostic implications. For instance, Li et al. [18] reported that the proportion of multiple gross lesions found in clear cell, giant cell, and sarcomatoid subtypes were $4.7 \%, 21 \%$, and $25 \%$ and the median survival period on follow up for these subtypes were 45,13 , and 8 months respectively. Moreover, several systematic reviews demonstrated that the fibrolamellar variant has a better prognosis than conventional HCC after hepatic surgical resection of the tumor with greater five-year overall survival [35] [36]. However, there are conflicting reports on the outcomes in pediatric age groups and young adults. For instance, Weeda and Katzestein et al. [37] [38] reported that there are no significant differences in overall survival of pediatric and adolescent patients diagnosed with fibrolamellar HCC and the typical HCC. Similarly, Moreno-Luna et al. [39] reported that children and young adults under the age of 23 years treated with surgical resection have a worse prognosis compared to patients above this age. Li et al. [15] reported that the histomorphological differentiation of HCC independently predicts post-transplant survival and recurrence rate in HBV associated HCC. See Table 2 for the different reports on the histologic variants of HCC in Nigeria and other countries. Aside from the histological 
Table 2. Shows the relative frequency of histologic variants of HCC in Nigeria and other countries.

\begin{tabular}{|c|c|c|c|c|c|c|c|c|}
\hline \multirow{2}{*}{$\begin{array}{c}\text { Serial } \\
\text { Number }\end{array}$} & \multirow{2}{*}{$\begin{array}{l}\text { Histological } \\
\text { Subtype }\end{array}$} & \multicolumn{4}{|c|}{ Nigeria } & \multirow{2}{*}{$\begin{array}{c}\text { Zaire } \\
{[32]}\end{array}$} & \multirow{2}{*}{$\begin{array}{c}\text { Kenya } \\
{[28]}\end{array}$} & \multirow{2}{*}{ Thailand [30] } \\
\hline & & Benin City* & Zaria [33] & $\mathrm{PH}[25]$ & Jos [31] & & & \\
\hline 1 & Pseudglandular & 44.07 & - & 28.06 & 13.20 & 0.90 & 1.20 & 5.00 \\
\hline 2 & Trabecular & 28.81 & - & 49.20 & 71.30 & 31.20 & 29.50 & 63.30 \\
\hline 3 & Solid & 16.95 & - & 16.04 & - & 13.30 & 48.80 & 15.60 \\
\hline 4 & Fibrolamellar & 10.17 & - & 2.70 & 1.00 & - & 7.70 & 0.60 \\
\hline 5 & Clear Cell & - & 3.22 & 4.00 & 6.60 & 0.40 & 10.30 & - \\
\hline 6 & Giant Cell & - & - & - & - & - & 2.50 & - \\
\hline 7 & Mixed & - & - & - & 7.90 & 48.20 & - & - \\
\hline 8 & Schirous & - & 1.61 & - & - & 6.00 & - & 7.8 \\
\hline 9 & Sarcomatoid & - & 1.61 & - & - & - & - & - \\
\hline 10 & Conventional & - & 93.56 & - & - & - & - & 7.8 \\
\hline Total (\%) & & 100.0 & 100.0 & 100.0 & 100.0 & 100.0 & 100.0 & 100.0 \\
\hline
\end{tabular}

${ }^{*}$ Current study, $\mathrm{PH}-$ Port-Harcourt.

variations, serum alpha-fetoprotein levels greater than $400 \mathrm{ng} / \mathrm{ml}$, TNM staging and portal venous thrombosis are important independent prognostic factors [13] [14] [18].

\section{Conclusion}

Hepatocellular carcinoma has different demographic and histological characteristics, hence understanding its protean morphology and ensuring comprehensive histological reporting would improve the clinical outcomes.

\section{Ethical Considerations}

Ethical approval for this research was obtained from the Medical Research Ethics Committee of the University of Benin Teaching Hospital Benin City.

\section{Conflicts of Interest}

The authors declare no conflicts of interest regarding the publication of this paper.

\section{References}

[1] El-Serag, H.B. (2004) Hepatocellular Carcinoma: Recent Trends in the United States. Gastroenterology, 127, S27-S34. https://doi.org/10.1053/j.gastro.2004.09.013

[2] Goodman, Z.D. (2007) Neoplasms of the Liver. Modern Pathology, 20, S49-S60. https://doi.org/10.1038/modpathol.3800682

[3] Vandelli, C. and Renzo, F. (2000) Hepatocellular Carcinoma: Role of Hepatitis Viruses and Liver Cell Dysplasia. Methods in Molecular Medicine, 45, 71-96. https://doi.org/10.1385/1-59259-079-9:71 
[4] Abdulkareem, F.B., Faduyile, F.A., Daramola, A.O., Rotimi, O., Banjo, A.A.F., Elesha, S.O., et al. (2009) Malignant Gastrointestinal Tumours in South-Western Nigeria: A Histopathologic Analysis of 713 Cases. West African Journal of Medicine, 28, 173-175. https://doi.org/10.4314/wajm.v28i3.48478

[5] Mandong, B.M., Madaki, A.K.J. and Mannaseh, A.N. (2003) Malignant Diseases in Jos: A Follow Up. Annals of African Medicine, 2, 49-53.

[6] Afolayan, E.A.O., Ibrahim, O.O.K. and Ayilara, G.T. (2012) Cancer Patterns in Ilorin: An Analysis of Ilorin Cancer Registry Statistics. Tropical Journal of Health Sciences, 19, 17-22.

[7] Malami, S.A., Pindiga, U.H., Abimiku, B.A., Mungadi, I.A., Abdullahi, A.D., Dauda, A., et al. (2007) A Descriptive Study of Pattern of Malignant Diseases in Sokoto, North-Western Nigeria (1999-2004). Journal of Medical Sciences, 7, 1033-1038.

[8] Wiredu, E.K. and Armah, H.B. (2006) Cancer Mortality Patterns in Ghana: A 10-Year Review of Autopsies and Hospital Mortality. BMC Public Health, 6, 159-165. https://doi.org/10.1186/1471-2458-6-159

[9] Seeff, L.B. and Hoofnagle, J.H. (2006) Epidemiology of Hepatocellular Carcinoma in Areas of Low Hepatitis B and Hepatitis C Endemicity. Oncogene, 25, 3771-3777.

[10] Poustchi, H., Sepanlou, S.G., Esmaili, S., Mehrabi, N. and Ansarymoghadam, A. (2010) Hepatocellular Carcinoma in the World and the Middle East. Middle East Journal of Digestive Diseases, 2, 98-102. https://doi.org/10.1038/sj.onc.1209560

[11] Murugavel, K.G., Naranatt, P.P., Shankar, E.M., Mathews, S., Raghuram, K., Rajasambandam, P., et al. (2007) Prevalence of Aflatoxin B1 in Liver Biopsies of Proven hepatocellular Carcinoma in India Determined by an In-House Immunoperoxidase Test. Journal of Medical Microbiology, 56, 1455-1459. https://doi.org/10.1099/jmm.0.47151-0

[12] Schlageter, M., Terracciano, L.M., D’Angelo, S. and Sorrentino, P. (2014) Histopathology of Hepatocellular Carcinoma. World Journal of Gastroenterology, 20, 15955-15964. https://doi.org/10.3748/wjg.v20.i43.15955

[13] Shafizadeh, N. and Kakar, S. (2013) Hepatocellular Carcinoma: Histologic Subtypes. Surgical Pathology Clinics, 6, 367-384. https://doi.org/10.1016/j.path.2013.03.007

[14] Li, Z., Wu, X., Bi, X., Zhang, Y., Huang, Z. and Lu, H. (2018) Clinicopathological Features and Surgical Outcomes of Four Rare Subtypes of Primary Liver Carcinoma. Chinese Journal of Cancer Research, 30, 364-372. http://www.cjcrcn.org/article/html_9811.html

[15] Wu, C. and Shan, H. (2012) Multivariate Analysis of Recurrence of Hepatocellular Carcinoma after Liver Transplantation. Chinese Medical Journal, 92, 2023-2027.

[16] Li, W.X., Li, Z., Gao, P.J., Gao, J. and Zhu, J.Y. (2014) Histological Differentiation Predicts Post-Liver Transplantation Survival Time. Clinics and Research in Hepatology and Gastroenterology, 38, 201-208. https://doi.org/10.1016/j.clinre.2013.11.002

[17] Chan, A.W., Tong, J.H., Pan, Y., Chan, S.L., Wong, G.L. and Wong, V.W. (2015) Lymphoepithelioma-Like Hepatocellular Carcinoma: An Uncommon Variant of Hepatocellular Carcinoma with Favourable Outcome. The American Journal of Surgical Pathology, 39, 304-312. https://doi.org/10.1097/PAS.0000000000000376

[18] Li, Z., Bi, X., Yang, L., Zhao, J., Zhao, H. and Huang, Z. (2014) A Clinicopathological and Prognostic Study of Rare Pathological Subtype Cases of Hepatocellular Carcinoma. Chinese Journal of Surgery, 52, 329-332.

[19] Njei, B., Konjeti, V.R. and Ditah, I. (2014) Prognosis of Patients with Fibrolamellar 
Hepatocellular Carcinoma versus Conventional Hepatocellular Carcinoma: A Systematic Review and Meta-Analysis. Gastrointestinal Cancer Research, 7, 49-54.

[20] Jain, D. (2014) Tissue Diagnosis of Hepatocellular Carcinoma. Journal of Clinical and Experimental Hepatology, 4, S67-S73.

https://doi.org/10.1016/j.jceh.2014.03.047

[21] Calderaro, J., Couchy, G., Imbeaud, S., Amaddeo, G., Letouzé, E. and Blanc, J. (2017) Histological Subtypes of Hepatocellular Carcinoma Are Related to Gene Mutations and Molecular Tumour Classification. Journal of Hepatology, 67, 727. https://doi.org/10.1016/j.jhep.2017.05.014

[22] Jain, D., Nayak, N.C., Kumaran, V. and Saigal, S. (2013) Steatohepatitic Hepatocellular Carcinoma, a Morphologic Indicator of Associated Metabolic Risk Factors: A Study from India. Archives of Pathology \& Laboratory Medicine, 137, 961-966. https://doi.org/10.5858/arpa.2012-0048-OA

[23] McGlynn, K.A., Tsao, L., Hsing, A.W., Devesa, S.S., Joseph, F. and Fraumeni, J.R. (2001) International Trends and Patterns of Primary Liver Cancer. International Journal of Cancer, 94, 290-296. https://doi.org/10.1002/ijc.1456

[24] Nwokediuko, S., Ijoma, U. and Obienu, O. (2011) Liver Cancer in Enugu, Southeast Nigeria. Insight Bioinformatics, 1, 1-5. https://doi.org/10.5567/BIOINFO-IK.2011.1.5

[25] Seleye-Fubara, D. and Jebbin, N.J. (2007) Hepatocellular Carcinoma in Port Harcourt, Nigeria: Clinicopathologic Study of 75 Cases. Annals of African Medicine, 6, 54-57. https://doi.org/10.4103/1596-3519.55716

[26] Ndububa, D.A., Ojo, O.S., Adeodu, O.O., Adetiloye, V.A., Olasode, B.J., Famurewa, O.C., et al. (2001) Primary Hepatocellular Carcinoma in Ile-Ife, Nigeria: A Prospective Study of 154 Cases. Nigerian Journal of Medicine, 10, 59-63.

[27] Chinombe, N., Chavhunduka, E. and Matarira, H.T. (2009) Seroprevalence of HBV and HCV in Primary Hepatocellularcarcinoma Patients in Zimbabwe. Infect Agents Cancer, 4, 15-20. https://doi.org/10.1186/1750-9378-4-15

[28] Mutuma, G.Z., Mbuchi, M.W., Zeyhle, E., Fasana, R., Okoth, F.A., Kabanga, J.M., et al. (2011) Prevalence of Hepatitis B Virus (HBV) Surface Antigen and HBV-Associated Hepatocellular Carcinoma in Kenyans of Various Ages. African Journal of Health Sciences, 18, 53-61.

[29] Leong, T.Y.-M. and Leong, A.S.-Y. (2005) Epidemiology and Carcinogenesis of Hepatocellular Carcinoma. $H P B, 7,5-15$. https://doi.org/10.1080/13651820410024021

[30] Schady, D.A., Roy, A. and Finegold, M.J. (2015) Liver Tumors in Children with Metabolic Disorders. Translational Pediatrics, 4, 290-303.

[31] Sooklim, K., Sriplung, H. and Piratvisuth, T. (2003) Histologic Subtypes of Hepatocellular Carcinoma in the Southern Thai Population. Asian Pacific Journal of Cancer Prevention, 4, 302-306.

[32] Vhriterhire, R.A., Ngbea, J.A., Ojo, B.A., Jegede, O.O., Manasseh, A.N., Ayuba, M.D., et al. (2016) Hepatocellular Carcinoma Sub-Types in North-Central Nigeria: A Histological Review of Liver Biopsies. British Journal of Medicine and Medical Research, 12, 1-8. https://doi.org/10.9734/BJMMR/2016/21772

[33] Kashala, L.O., Conne, B., Kalengayi, M.M., Kapanci, Y., Frei, P.C. and Lambert, P.H. (1990) Histopathologic Features of Hepatocellular Carcinoma in Zaire. Cancer, 65, 130-134. https://doi.org/10.1002/1097-0142(19900101)65:1<130::AID-CNCR2820650126>3.0 
$\underline{\mathrm{CO} ; 2-\mathrm{S}}$

[34] Bello, U., Omotara, S.M. and Yawale, I. (2016) Hepatocellular Carcinoma in Zaria: An Analysis of the Morphology and Associated Risk Factors. Annals of Tropical Pathology, 7, 96-101.

[35] Mavros, M.N., Mayo, S.C., Hyder, O. and Pawlik, T.M. (2012) A Systematic Review: Treatment and Prognosis of Patients with Fibrolamellar Hepatocellular Carcinoma. Journal of the American College of Surgeons, 215, 820-830. https://doi.org/10.1016/j.jamcollsurg.2012.08.001

[36] Stipa, F., Yoon, S.S., Liau, K.H., Fong, Y., Jarnagin, W.R., D’Angelica, M., et al. (2006) Outcome of Patients with Fibrolamellar Hepatocellular Carcinoma. Cancer, 106, 1331-1338. https://doi.org/10.1002/cncr.21703

[37] Weeda, V.B., Murawski, M., McCabe, A.J., Maibach, R., Brugie'res, L., Roebuck, D., et al. (2013) Fibrolamellar Variant of Hepatocellular Carcinoma Does Not Have a Better Survival than Conventional Hepatocellular Carcinoma-Results and Treatment Recommendations from the Childhood Liver Tumour Strategy Group (SIOPEL) Experience. European Journal of Cancer, 49, 2698-2704.

https://doi.org/10.1016/j.ejca.2013.04.012

[38] Katzenstein, H.M., Krailo, M.D., Malogolowkin, M.H., Ortega, J.A., Qu, W., Douglass, E.C., et al. (2003) Fibrolamellar Hepatocellular Carcinoma in Children and Adolescents. Cancer, 97, 2006-2012. https://doi.org/10.1002/cncr.11292

[39] Moreno-Luna, L.E., Arrieta, O., García-Leiva, J., Martínez, B., Torre, A., Uribe, M., et al. (2005) Clinical and Pathologic Factors Associated with Survival in Young Adult Patients with Fibrolamellar Hepatocarcinoma. BMC Cancer, 5, 142. https://doi.org/10.1186/1471-2407-5-142 